\title{
Kinetics on NiZn Bimetallic Catalysts for Hydrogen Evolution via Selective Dehydrogenation of Methylcyclohexane to Toluene
}

\author{
Anaam H. Al-ShaikhAli, ${ }^{\dagger}$ Abdesslem Jedidi, ${ }^{\S}$ Dalaver H. Anjum, ${ }^{\ddagger}$ Luigi Cavallo, ${ }^{*}{ }^{\dagger}$ (1) \\ and Kazuhiro Takanabe* ${ }^{* \dagger}$
}

\begin{abstract}
${ }^{\dagger}$ King Abdullah University of Science and Technology (KAUST), KAUST Catalysis Center (KCC) and Physical Science and Engineering Division (PSE), 4700 KAUST, Thuwal, 23955-6900, Saudi Arabia

${ }^{\S}$ Department of Chemistry, King Abdulaziz University, Jeddah 21589, Saudi Arabia

${ }^{\ddagger}$ King Abdullah University of Science and Technology (KAUST), Imaging and Characterization Core Lab, 4700 KAUST, Thuwal, 23955-6900 Saudi Arabia
\end{abstract}

Supporting Information

ABSTRACT: Liquid organic chemical hydrides are effective hydrogen storage media for easy and safe transport. The chemical couple of methylcyclohexane $(\mathrm{MCH})$ and toluene (TOL) has been considered one of the feasible cycles for a hydrogen carrier, but the selective dehydrogenation of $\mathrm{MCH}$ to TOL has been reported using only Ptbased noble metal catalysts. This study reports $\mathrm{MCH}$ dehydrogenation to TOL using supported NiZn as a selective, non-noble-metal catalyst. A combined experimental and computational study was conducted to provide insight into the site requirements and reaction mechanism for $\mathrm{MCH}$ dehydrogenation to TOL, which were compared with those for cyclohexane $(\mathrm{CH})$ dehydrogenation to benzene (BZ). The kinetic measurements carried out at $300-360{ }^{\circ} \mathrm{C}$ showed an almost zero order with respect to $\mathrm{MCH}$ pressure in the high-pressure region $(\geq 10 \mathrm{kPa})$ and nearly a positive half order with respective to $\mathrm{H}_{2}$ pressure $(\leq 40 \mathrm{kPa})$. These kinetic data for the dehydrogenation reaction paradoxically indicate that hydrogenation of a strongly chemisorbed intermediate originating from TOL is the rate-determining step. Density functional theory (DFT) calculation confirms that the dehydrogenated TOL species at the aliphatic (methyl) position group $\left(\mathrm{C}_{6} \mathrm{H}_{5} \mathrm{CH}_{2}\right)$ were strongly adsorbed on the surface, which must be hydrogenated to desorb as TOL. This hydrogen-assisted desorption mechanism explains the essential role of excess $\mathrm{H}_{2}$ present in the feed in maintaining the activity of the metallic surface for hydrogenation. The rate of the $\mathrm{CH}$ to $\mathrm{BZ}$ reaction was less sensitive to $\mathrm{H}_{2}$ pressure than that of $\mathrm{MCH}$ to TOL, which can be explained by the absence of a methyl group in the structure, which in turn reduces the binding energy of the adsorbed species. DFT suggests that the improved TOL selectivity by adding $\mathrm{Zn}$ to Ni was due to $\mathrm{Zn}$ atoms preferentially occupying low-coordination sites on the surface (the corner and edge sites), which are likely the unselective sites responsible for the $\mathrm{C}-\mathrm{C}$ dissociation of the methyl group of TOL.

KEYWORDS: dehydrogenation, methylcyclohexane, toluene, NiZn, density functional theory

\section{INTRODUCTION}

Hydrogen $\left(\mathrm{H}_{2}\right)$ has been utilized as an environmentally attractive fuel and a primary energy carrier, especially when produced from renewable energies. It links a host of energy sources to various mobile applications and should empower a secure and clean energy future. ${ }^{1-4}$ It can be correspondingly released for use in a fuel cell to power an electrical engine with superior efficiency. ${ }^{5,6}$ The key to using $\mathrm{H}_{2}$ on a large scale, however, relies on its safe and efficient storage, transportation, and distribution. Liquid organic hydride cycles, such as methylcyclohexane (MCH)-toluene (TOL), store $\mathrm{H}_{2}$ in the form of chemical bonds (with an energy storage of $\Delta H^{\circ} 205.2$ $\mathrm{kJ} \mathrm{mol}^{-1}$ ) and are highly effective for long-distance transport and successive use as a $\mathrm{H}_{2}$ source for many applications (e.g., fuel cells). ${ }^{7-9}$ The $\mathrm{H}_{2}$ supply cost from liquid organic hydrides is reported to be 20 and $30 \%$ lower than compressed hydrogen and liquefied hydrogen, respectively. ${ }^{10-12}$ The development of a highly active and selective dehydrogenation catalyst with a low deactivation rate is crucial for industrial applications. Therefore, the development of a mechanistic kinetic model for the selective dehydrogenation of $\mathrm{MCH}$ to $\mathrm{TOL}$ (without introducing the undesired breaking of the exocyclic $\mathrm{C}-\mathrm{C}$ bond of TOL) over any developed catalyst is the first step to overcoming these technical restrictions.

We reported in our previous work that Ni-based bimetallic catalysts offer an attractive solution for the selective

Received: November 19, 2016

Revised: January 16, 2017

Published: January 18, 2017 
dehydrogenation of $\mathrm{MCH}$ to TOL, which may potentially replace Pt-based catalysts. ${ }^{13}$ We reported that the bimetallic $\mathrm{NiZn} / \mathrm{Al}_{2} \mathrm{O}_{3}$ catalyst exhibits a superb selectivity to TOL compared to the monometallic $\mathrm{Ni} / \mathrm{Al}_{2} \mathrm{O}_{3}$ catalyst. ${ }^{13}$ The $\mathrm{Ni}$ catalyst led to a reduction of selectivity by producing $\mathrm{CH}_{4}$ and benzene (BZ) as a consequence of $\mathrm{C}-\mathrm{C}$ scission and hydrogenation of the methyl group from the aromatic ring in TOL. ${ }^{13}$ The improved selectivity with addition of $\mathrm{Zn}$ was mostly attributed to poisoning of the unselective step sites of $\mathrm{Ni}$ by $\mathrm{Zn}$, as predicted by DFT. ${ }^{13}$ Similar effects of improved selectivity using NiZn alloy were reported for the hydrogenation of acetylene to ethylene. ${ }^{14-18}$ The proposed mechanism was based on the adsorption properties of ethylene, which can be particularly competitive at step sites and other low-coordinated sites on the catalyst surface, and these reactive sites could be poisoned by the addition of $\mathrm{Zn}$. This assumption proposes that $\mathrm{Zn}$ could alter the $\mathrm{Ni}$ surface by poisoning lowcoordinated $\mathrm{C}-\mathrm{C}$ bond-breaking sites. ${ }^{14}$

Little information is available in the literature for $\mathrm{MCH}$ dehydrogenation using Ni-based catalysts. ${ }^{19-22}$ The aim of this work is to provide insight into the mechanistic details for dehydrogenation of $\mathrm{MCH}$ to TOL over the bimetallic NiZnbased catalyst using experiments and DFT calculations. The results are effectively compared with the monometallic Pt and Ni-based catalysts. For deep understanding of surface intermediate species, the dehydrogenation of cyclohexane $(\mathrm{CH})$ to $\mathrm{BZ}$ was also investigated. A substantial difference between $\mathrm{CH}$ and $\mathrm{MCH}$ was evident for the reaction, resulting from high impact of the methyl group in the chemical structure. The effects of the $\mathrm{Zn}$ addition to $\mathrm{Ni}$ are discussed by DFT calculation.

\section{EXPERIMENTAL SECTION}

Catalyst Preparation. The $\mathrm{NiZn} / \mathrm{Al}_{2} \mathrm{O}_{3}$ and $\mathrm{Ni} / \mathrm{Al}_{2} \mathrm{O}_{3}$ catalysts used in this study were prepared using a homogeneous deposition precipitation method (the detailed procedure is shown in the Supporting Information ESI). Briefly, $\mathrm{Al}_{2} \mathrm{O}_{3}$ (Alfa Aesar) treated at $500{ }^{\circ} \mathrm{C}\left(218 \mathrm{~m}^{2} \mathrm{~g}^{-1}\right)$ was mixed with a solution containing the required amounts of $\mathrm{NiCl}_{2} \cdot 6 \mathrm{H}_{2} \mathrm{O}$ (Sigma-Aldrich, purity 99.999\%), $\mathrm{ZnNO}_{3} \cdot 6 \mathrm{H}_{2} \mathrm{O}$ (purity $\geq 99 \%$ ), and urea (Sigma-Aldrich, purity $99.5 \%$ ) with a molar ratio of urea $/(\mathrm{Ni}+\mathrm{Zn})=100$. The solution was heated at $90{ }^{\circ} \mathrm{C}$, which causes urea hydrolysis. This step was followed by the addition of $100 \mathrm{~mL}$ of ethylene glycol (EG, purity $\geq 99 \%$ ) at room temperature and subsequent heat treatment to $120^{\circ} \mathrm{C}$ for $1 \mathrm{~h}$ under refluxing conditions. The obtained slurry was filtered and washed with copious amounts of water $(600 \mathrm{~mL})$ followed by $100 \mathrm{~mL}$ of ethanol (purity $99.96 \%$, VWR chemical). The resulting sample was dried at $70{ }^{\circ} \mathrm{C}$ overnight before catalytic tests. The commercial 1 wt $\% \mathrm{Pt} / \mathrm{Al}_{2} \mathrm{O}_{3}$ was obtained from Sigma-Aldrich ( $3.2 \mathrm{~mm}$ pellets) and used for comparison. Actual metal loading was measured using inductively coupled plasma (ICP).

Kinetic Study. The rates and selectivities were measured in a flow reactor using a U-shaped tubular quartz reactor. The catalysts were first pelletized, crushed into 150-250 $\mu \mathrm{m}$ particles, and packed with a small amount of quartz wool. The temperature was maintained using a Honeywell controller, which was coupled to a resistively heated furnace and measured with a K-type thermocouple set outside the catalyst bed. $\mathrm{MCH}$ or $\mathrm{CH}$ was introduced using a Brooks direct liquid vaporizer, Model DLIHV 6000W with Ar (Abdullah Hashim Industrial Gases and Equipment Co., Ltd., purity 99.9999\%) as a carrier gas. The catalytic reactor lines were heated at $\sim 150{ }^{\circ} \mathrm{C}$ to prevent condensation. The gas compositions were quantified using an online gas chromatograph (Shimadzu GC-8A) with a Chromosorb W AW-DMCS column and a flame ionization detector (FID). Prior to the test, the catalysts were reduced in situ for $30 \mathrm{~min}$ at $400{ }^{\circ} \mathrm{C}$ under a flow of $\mathrm{H}_{2}\left(99.999 \%, \mathrm{H}_{2}\right.$ generator $\mathrm{NMH}_{2} 300 \mathrm{DBS}$ analytical instrument, $30 \mathrm{~mL} \mathrm{~min}^{-1}$ ) and $\operatorname{Ar}\left(30 \mathrm{~mL} \mathrm{~min}{ }^{-1}\right)$. Thermodynamic equilibrium calculation was carried out, and the results are shown in Figure S1.

Catalyst Characterization. Probe-corrected scanning transmission electron microscopy (STEM) images were taken using a model Titan 80-300 ST from FEI Company (Hillsboro, OR). The fresh and used catalysts were suspended on 200 mesh copper grids coated with holey-carbon. The microscope was operated at an accelerating voltage of $300 \mathrm{kV}$, and its spherical aberration coefficient (Cs) was reduced to $0.001 \mathrm{~mm}$ using the probe-corrector. The STEM images were recorded with a high-angle annular dark-field (HAADF) detector. Electron energy loss spectroscopy (EELS) analysis, employing a GIF Quantum 966 spectrometer from Gatan, Inc., of the samples was performed along with the HAADF-STEM investigations. In this way, several STEM-EELS spectrumimaging (SI) data sets from different locations on the specimens were acquired to investigate the distributions of $\mathrm{Ni}$ and $\mathrm{Zn}$ elements on the $\mathrm{Al}_{2} \mathrm{O}_{3}$ support. The STEM-EELS SI data sets were acquired to have the $\mathrm{L}_{23}$ edge of $\mathrm{Ni}\left(\mathrm{Ni}-\mathrm{L}_{23}\right)$, the $\mathrm{L}_{23}$ edge of $\mathrm{Zn}\left(\mathrm{Zn}-\mathrm{L}_{23}\right)$, and the $\mathrm{K}$-edge of $\mathrm{Al}(\mathrm{Al}-\mathrm{K})$ at the energy losses of 855, 1020, and $1560 \mathrm{eV}$, respectively. The entire data acquisition and analysis process was carried out in Gatan Microscopy Suite (GMS) of version 2.3 from Gatan, Inc.

The $\mathrm{N}_{2}$ sorption studies were conducted using a Micromeritics ASAP 2420 to determine the Brunauer-EmmettTeller (BET) surface area.

ICP measurements were performed using an Agilent 720 Series ICP-OES instrument (Agilent Technologies). The material was digested in an ETHOS 1 microwave digestion system (Milestone Srl).

Powder X-ray diffraction (XRD) patterns were measured using a BRUKER D8 advance diffractometer (DMAX 2500) using a $\mathrm{Cu} \mathrm{K} \alpha$ energy source at $40 \mathrm{kV}$ and $40 \mathrm{~mA}(\lambda=0.154$ $\mathrm{nm})$.

Computational Details. Electronic structure calculations were performed based on Density Functional Theory (DFT) using the revised Perdew-Burke-Ernzerhof (revPBE) exchange-correlation functional as implemented in the VASP code. ${ }^{23-26}$ Plane-wave basis sets (with a kinetic energy cutoff of $350 \mathrm{eV})^{27}$ describe the valence electrons: 10 electrons of $\mathrm{Ni}$ $\left(3 d^{8} 4 s^{2}\right)$ and 12 electrons of $\mathrm{Zn}\left(3 \mathrm{~d}^{10} 4 \mathrm{~s}^{2}\right)$. We employed a 0.1 $\mathrm{eV}$ smearing of the Fermi-level and $(8 \times 8 \times 8) \mathrm{K}$-points for bulk calculations and $(4 \times 4 \times 1)$ for surfaces. The core electrons were replaced by projector augmented wave (PAW) pseudopotentials. $^{28,29}$ The relaxation of the atomic positions in the supercell occurred until the energy differences were smaller than $0.01 \mathrm{eV} \AA^{-1}$. With this setup, the electronic structure of $\mathrm{Ni} / \mathrm{Zn}$ alloys was simulated using the cluster expansion (CE) method. $^{30,31}$ This method consists of the search for stable substitution of $\mathrm{Ni}$ atoms by $\mathrm{Zn}$ atoms in Ni nanoparticles (NP). NPs containing 55 and $147 \mathrm{Ni}$ atoms were considered.

To investigate the possible impact of $\mathrm{Zn}$ alloying on the electronic structure of $\mathrm{Ni}$, we compared the density of states (DOS) of $\mathrm{Ni} / \mathrm{Zn}$ alloys with increasing $\mathrm{Zn}$ content. Namely, we considered $\mathrm{Ni} / \mathrm{Zn}$ compositions of 100/0, 75/25, 50/50, 25/ 
$75,0 / 100$. The structures of the $\mathrm{Ni} / \mathrm{Zn}$ alloys were modeled using the special quasirandom structures (SQS) proposed for the study of properties of fcc-based alloys. ${ }^{32}$

To investigate the preferential sites for Ni substitution by $\mathrm{Zn}$ atoms, a cluster and a surface model were considered. The cluster model was represented by $\mathrm{Ni}_{55}$ and by $\mathrm{Ni}_{147} \mathrm{NPs}$. For the $\mathrm{Ni}_{55} \mathrm{NP}$, we compared the icosahedral and the cuboctahedral geometries. ${ }^{33,34}$ Because the icosahedral geometry is more stable than the cuboctahedral geometry by $3.75 \mathrm{eV}$, only the former geometry for the $\mathrm{Ni}_{147} \mathrm{NP}$ was considered. As VASP is a periodic code, these NPs were placed in a repeating cubic box with an edge large enough to prevent interactions between the images (more than $10 \AA$ between successive images). The surface model was represented by slabs of four atomic layers corresponding to the (100) facet of Ni. A p $(3 \times$ 3) supercell was used with vacuum in the direction perpendicular to the surface of $12 \AA$. To investigate different aspects of $\mathrm{MCH}$ to TOL conversion, the relative stability of various key intermediates was compared, which can be formed in the course of the reaction, adsorbed on the (100) facet of Ni.

To benchmark the computational protocol, the experimental standard enthalpy for the hydrogenation of TOL to MCH was calculated with the Gaussian09 program using the revised PBE functional in connection with the triple- $\zeta$ TZVP basis set, thus mimicking the VASP protocol. As common, thermochemical data of reactions involving single molecules is estimated with molecular codes, where very effective algorithms for the calculation of analytic second derivatives are implemented. This is different from standard solid-state programs, where second derivatives are calculated via extremely more expensive numerical differentiation of first derivatives. For the same reason, we limit the discussion to potential energies, rather than free energies, for intermediates in the reaction. For example, accurate evaluation of second derivatives for adsorbed TOL would require the calculations of 90 first derivatives corresponding to double displacement of each of the 15 atoms of TOL along the $x y z$ axes from the equilibrium position.

\section{RESULTS AND DISCUSSION}

Kinetic Study for MCH and $\mathrm{CH}$ Dehydrogenation. The NiZn catalyst was tested for $\mathrm{MCH}$ and $\mathrm{CH}$ dehydrogenation for $100 \mathrm{~h}$ (Figure 1; $\mathrm{MCH}$ or $\mathrm{CH}, 10 \mathrm{kPa} ; \mathrm{H}_{2}, 30 \mathrm{kPa}, 300^{\circ} \mathrm{C}$ ). The results showed an initial decay of $\sim 25 \%$ in the first $10 \mathrm{~h}$, followed by stable performance for the rest of the $100 \mathrm{~h}$. The $\mathrm{CH}$ conversion was slightly higher than the $\mathrm{MCH}$ conversion. A high selectivity of $>99.9 \%$ was obtained for $\mathrm{CH}$ to $\mathrm{BZ}$ throughout the $100 \mathrm{~h}$, and a selectivity of $\sim 99.5 \%$ was maintained for $100 \mathrm{~h}$ for $\mathrm{MCH}$ to TOL. Under the same condition, the monometallic $\mathrm{Ni}$ catalyst shows similar conversions, and the selectivity was also high for $\mathrm{CH}$ to $\mathrm{BZ}$, but a slight loss of selectivity was observed for $\mathrm{MCH}$ to TOL ( $\sim 97 \%)$ due to formation of $\mathrm{CH}_{4}$ and $\mathrm{BZ}$ as a consequence of $\mathrm{C}-\mathrm{C}$ cleavage of the methyl group. The selectivity loss was from both primary (directly from $\mathrm{MCH}$ ) and secondary (TOL) reactions, as reported in our previous communication. ${ }^{13}$ Based on this result, the partial pressure dependence was measured after the stability test of $12 \mathrm{~h}$.

Let us first focus on the $\mathrm{MCH}$ dehydrogenation reaction. The $\mathrm{H}_{2}$ and $\mathrm{MCH}$ partial pressure dependence on the turnover frequency (TOF) for the $\mathrm{MCH}$ conversion on $\mathrm{Ni} / \mathrm{Al}_{2} \mathrm{O}_{3}$ and $\mathrm{NiZn} / \mathrm{Al}_{2} \mathrm{O}_{3}$ was investigated at $300{ }^{\circ} \mathrm{C}$ in the kinetic region with relatively low $\mathrm{MCH}$ conversions $(<10 \%)$. TOF was calculated on the basis of the average particle size observed in
(A)
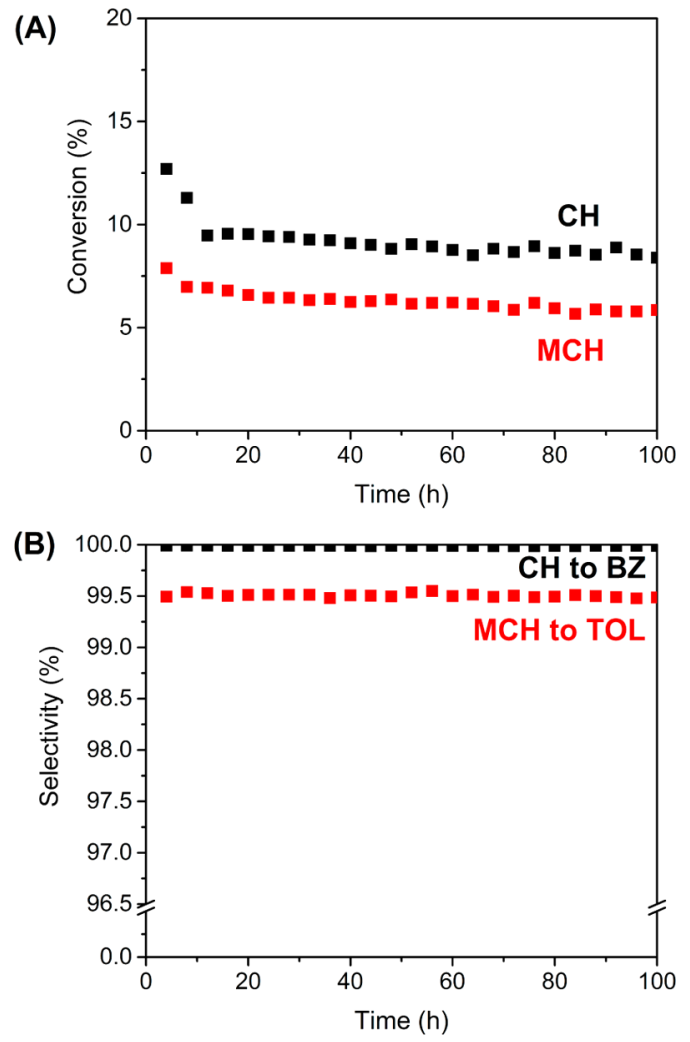

Figure 1. Time on stream of (A) conversion and (B) selectivity for $\mathrm{MCH}$ to TOL and $\mathrm{CH}$ to $\mathrm{BZ}\left(100 \mathrm{mg}, 300^{\circ} \mathrm{C}\right.$, pretreated at $400{ }^{\circ} \mathrm{C}$ in $\mathrm{H}_{2}$ for $1 \mathrm{~h}, 10 \mathrm{kPa} \mathrm{MCH}$ or $\mathrm{CH}, 30 \mathrm{kPa} \mathrm{H}_{2}, 1.7 \times 10^{-5} \mathrm{~g} \mathrm{~h} \mathrm{~mL}^{-1}$ ).

the (S)TEM images (Figure S2, Table S1). The response of the TOF for $\mathrm{MCH}$ conversion to the change in reactant partial pressures is shown in Figure 2. For both $\mathrm{Ni} / \mathrm{Al}_{2} \mathrm{O}_{3}$ and $\mathrm{NiZn} /$ $\mathrm{Al}_{2} \mathrm{O}_{3}$, the TOF was found to be almost half order with respective to $\mathrm{H}_{2}$ partial pressure (Figure 2A). For the $\mathrm{MCH}$ pressure, the TOF increased only at low $\mathrm{MCH}$ pressure and became unchanged beyond $10 \mathrm{kPa} \mathrm{MCH}$ (Figure 2B). The positive order in $\mathrm{H}_{2}$ pressure suggests that $\mathrm{H}$-derived species are involved in rate-determining step (rds), which will be discussed later in more detail. The partial pressure dependence of $\mathrm{MCH}$ and $\mathrm{H}_{2}$ was also investigated for $\mathrm{Pt} / \mathrm{Al}_{2} \mathrm{O}_{3}$ for comparison (Figure S3). The TOF was almost insensitive to $\mathrm{H}_{2}$ at all pressure ranges and beyond $\mathrm{MCH} \sim 10 \mathrm{kPa}$. Similar kinetic results for a $\mathrm{Pt}$ catalyst were reported in the literature. ${ }^{35-38}$

This observation of positive order in $\mathrm{H}_{2}$ pressure may contradict the general principles of the $\mathrm{MCH}$ dehydrogenation as $\mathrm{H}_{2}$ is a "product of dehydrogenation". The reason behind the above observation may be the fact that the presence of $\mathrm{H}_{2}$ is essential to facilitate TOL desorption ( $\mathrm{H}$-assisted desorption mechanism). For all the catalysts, the high presence of $\mathrm{H}_{2}$ (typically higher than $10 \mathrm{kPa}$ ) was essential to maintain a constant catalyst activity. $\mathrm{H}_{2}$ acts as a promoter that continuously cleans the surface of metallic active sites and minimizes the catalyst deactivation. On the other hand, the saturation behavior of TOF at higher $\mathrm{MCH}$ partial pressure $(\geq 10 \mathrm{kPa})$ suggests that the adsorbed TOL species that are formed substantially cover the active surface. Consequently, the reaction is fractional order with respect to $\mathrm{MCH}$ partial pressure and becomes zero-order at high $\mathrm{MCH}$ pressure. It is considered that the aromatic hydrocarbons strongly chemisorb 
(A)

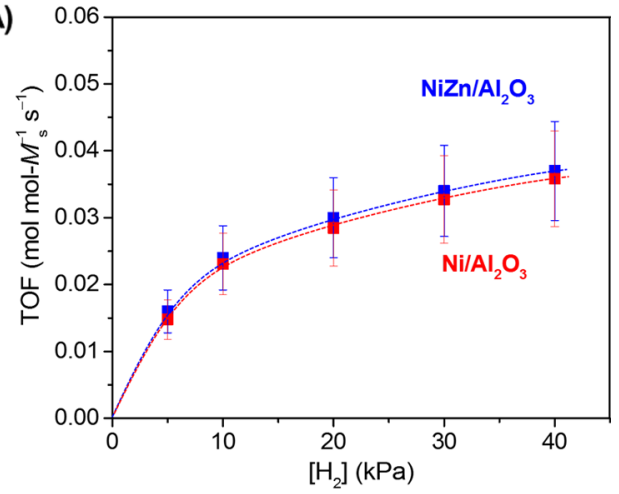

(B)

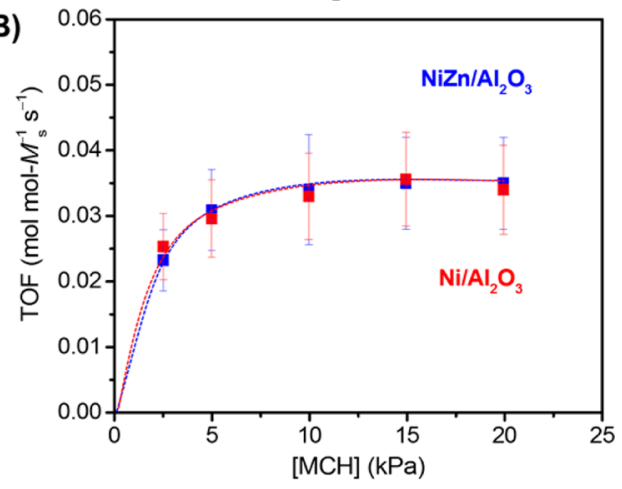

Figure 2. Effects of (A) $\mathrm{H}_{2}$ and (B) $\mathrm{MCH}$ partial pressures on TOF for $\mathrm{MCH}$ conversion $\left(20 \mathrm{mg}, 300{ }^{\circ} \mathrm{C}\right.$, (A) $10 \mathrm{kPa} \mathrm{MCH}$, (B) $30 \mathrm{kPa}$ $\left.\mathrm{H}_{2}, 1.7 \times 10^{-5} \mathrm{~g} \mathrm{~h} \mathrm{~mL}^{-1}\right)$.

on the metal surface, which is accompanied by extensive decomposition to form hydrogen-deficient surface residues, consistent with chemisorption studies on well-faceted $\mathrm{Ni}$ surfaces. ${ }^{39}$ Positive kinetic order for $\mathrm{H}_{2}$ suggests that $\mathrm{H}_{2}-$ derived species are involved in the rate-determining step, which may be hydrogenation of a $\mathrm{H}$-deficient hydrocarbon surface species. ${ }^{40-42}$

Comparative kinetic studies were conducted for the $\mathrm{CH}$ dehydrogenation reaction. The main difference is the methyl group on the aromatic ring. The partial pressure dependencies for $\mathrm{H}_{2}$ and $\mathrm{CH}$ were measured, and the results are shown in Figure 3. The increase in TOF was observed only up to $10 \mathrm{kPa}$ for $\mathrm{H}_{2}$ and became insensitive to $\mathrm{H}_{2}$ pressure beyond this pressure for both the $\mathrm{Ni}$ and NiZn catalysts (Figure 3A). The TOF with respective to $\mathrm{CH}$ pressure was zero-order for the $\mathrm{Ni}$ catalyst and fractional order for the NiZn catalyst, resulting in an unchanged TOF at high pressures $(>10 \mathrm{kPa})$ (Figure 3B). This indicates that the $\mathrm{CH}$ dehydrogenation over Ni-based catalyst is less sensitive to the amount of $\mathrm{H}_{2}$ introduced during the reaction, compared to $\mathrm{MCH}$ dehydrogenation. In fact, similar to the case of $\mathrm{MCH}$ dehydrogenation, the presence of excess $\mathrm{H}_{2}$ was essential to maintain high catalytic stability. These results imply that the $\mathrm{H}$-assisted desorption of $\mathrm{BZ}$ may also be true, but its desorption should be easier than TOL desorption, providing a distinctive $\mathrm{H}_{2}$ kinetic order $(\mathrm{MCH}$ : $0.5, \mathrm{CH}: \sim 0$ for $\mathrm{H}_{2}$ at high pressures). For Pt catalysts (Figure S4), the TOF was insensitive to both the $\mathrm{H}_{2}$ and $\mathrm{CH}$ pressures for $\mathrm{CH}$ dehydrogenation in the pressure range investigated.

Thermodynamics of TOL and BZ Adsorption on Ni Surfaces. The distinctive kinetics, especially the $\mathrm{H}_{2}$ dependence, may be strongly associated with surface-bound carbonaceous intermediates from TOL and BZ. DFT calculation was used to calculate the thermodynamics of TOL and BZ by
(A)

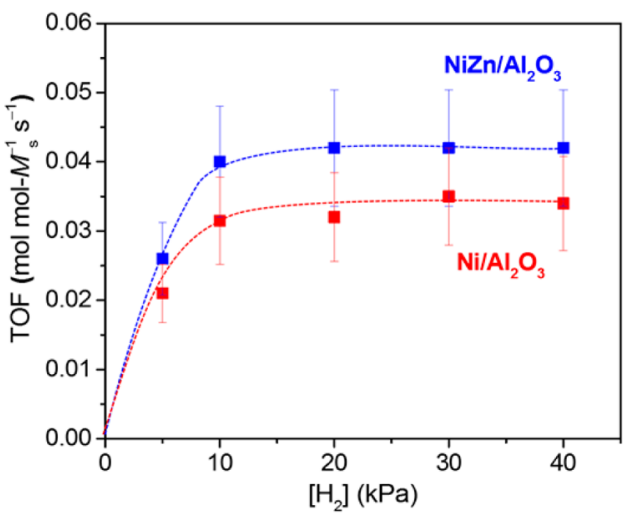

(B)

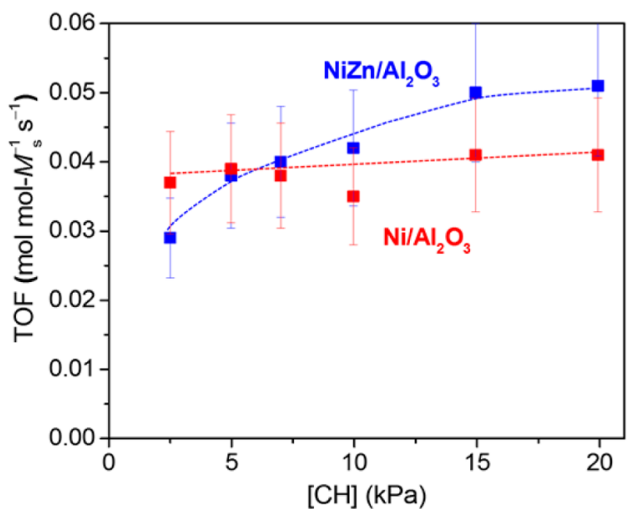

Figure 3. Effects of (A) $\mathrm{H}_{2}$ and (B) $\mathrm{CH}$ partial pressures on TOF for $\mathrm{CH}$ conversion $\left(20 \mathrm{mg}, 300{ }^{\circ} \mathrm{C}\right.$, (A) $10 \mathrm{kPa} \mathrm{CH}$, (B) $30 \mathrm{kPa} \mathrm{H}_{2}, 1.7 \times$ $\left.10^{-5} \mathrm{~g} \mathrm{~h} \mathrm{~mL}^{-1}\right)$.

comparing the geometry and adsorption energy, $E_{\mathrm{ads}}$, on a regular (100) Ni surface (Figure 4). Before discussing adsorbed species, we remark that the experimental $\Delta H^{\circ}$ of $205.2 \mathrm{~kJ}$ $\mathrm{mol}^{-1}$ for the hydrogenation of TOL to $\mathrm{MCH}$ is reasonably well reproduced by the chosen computational setup, with a $\Delta H^{\circ}$ of $185 \mathrm{~kJ} \mathrm{~mol}^{-1}$. This also gives an indication of the

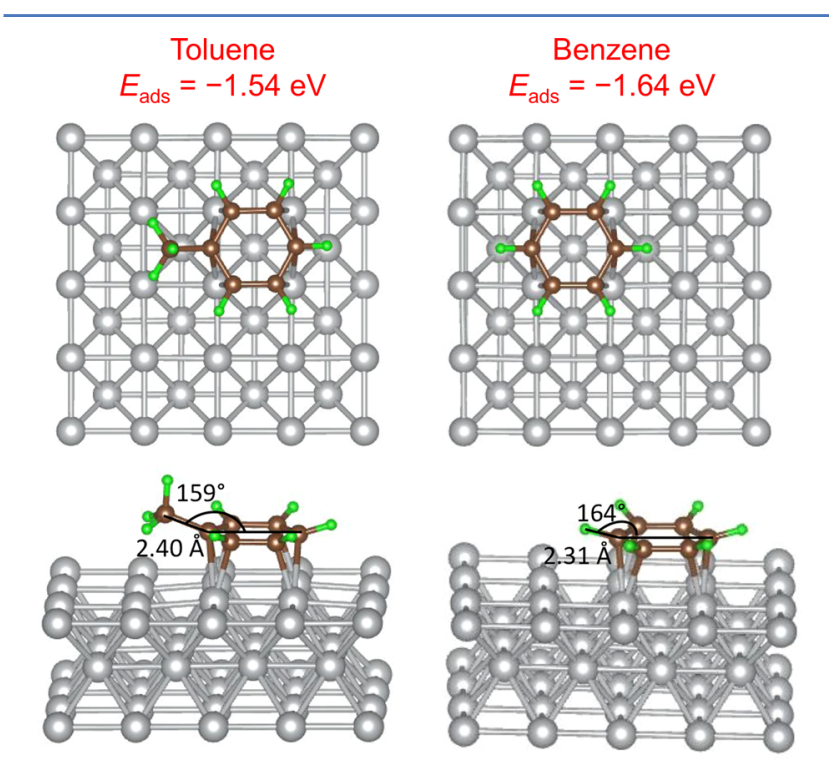

Figure 4. Geometry of TOL and BZ adsorbed on the $\mathrm{Ni}(100)$ surface. The shortest $\mathrm{Ni}-\mathrm{C}_{\mathrm{ipso}}$ distance for $\mathrm{TOL}$, and a similar $\mathrm{Ni}-\mathrm{C}$ distance in $\mathrm{BZ}$ is reported, together with the $\mathrm{C}_{\mathrm{para}}-\mathrm{C}_{\text {ipso }}-\mathrm{Me}$ angle for $\mathrm{TOL}$, and a similar $\mathrm{C}-\mathrm{C}-\mathrm{H}$ angle in $\mathrm{BZ}$. 
expected accuracy of the energies discussed in the following. Moving to adsorbed species, as expected for both TOL and BZ, assumes a flat adsorption geometry to maximize interaction between the aromatic $\pi$-skeleton of the adsorbed molecule with surface atoms. The top view of the optimized geometries show that 4 of the $\mathrm{C}$ atoms of the aromatic ring of both TOL and BZ are on top of a $\mathrm{Ni}$ atom, while the two other $\mathrm{C}$ atoms, in relative para positions, are bridging between two $\mathrm{Ni}$ atoms. In the case of TOL, the most stable geometry has the $\mathrm{C}_{\text {ipso }}$ atom, which is the $\mathrm{C}$ atom bonded to the methyl group, on top of a $\mathrm{Ni}$ atom. According to the calculations, $\mathrm{BZ}\left(E_{\mathrm{ads}}:-1.64 \mathrm{eV}\right)$ binds slightly stronger than TOL $\left(E_{\text {ads }}:-1.54 \mathrm{eV}\right)$ on the $\mathrm{Ni}(100)$ surface. This difference can be ascribed to a small deviation from the optimal interaction between the aromatic ring of TOL and the Ni surface due to the presence of the methyl functional group in TOL, as evidenced by the slightly longer adsorption distance of the $\mathrm{C}_{\text {ipso }}$ atom of TOL from the $\mathrm{Ni}$ mean plane, relative to the distance of the corresponding $\mathrm{C}$ atoms of BZ, and by the slightly higher out-of-plane bending of the methyl group of TOL relative to a $\mathrm{H}$ atom in $\mathrm{BZ}$.

In the second step, dissociation of a $\mathrm{C}-\mathrm{H}$ bond from different position of BZ and TOL was modeled, and the results are shown in Table 1 . Starting with BZ, analysis of the data

Table 1. First and Second C-H Dissociation Energy, $E_{\text {diss }}$, in $\mathrm{eV}$ from TOL and $\mathrm{BZ}$

\begin{tabular}{llr}
\multicolumn{1}{c}{ molecule } & \multicolumn{1}{c}{$\mathrm{C}-\mathrm{H}$ position } & $\begin{array}{c}E_{\text {diss }} \\
(\mathrm{eV})\end{array}$ \\
TOL 1st $\mathrm{C}-\mathrm{H}$ dissociation & methyl group & -0.61 \\
& ortho on top of a Ni & 0.87 \\
& meta on top of a Ni & 0.84 \\
& para on top of a Ni & 0.82 \\
TOL $\left(\mathrm{C}_{6} \mathrm{H}_{5} \mathrm{CH}_{2}\right)$ 2nd C-H dissociation & $\mathrm{CH}_{2}$ & 1.02 \\
& ortho & 1.29 \\
& meta & 1.40 \\
BZ 1st C-H dissociation & para & 1.45 \\
BZ 2nd C-H dissociation & $\mathrm{C}$ on top of a $\mathrm{Ni}$ & 0.89 \\
& $\mathrm{C}$ bridging two $\mathrm{Ni}$ & 1.34 \\
& ortho & 0.55 \\
& meta & 0.72 \\
& para & 0.76
\end{tabular}

reported in Table 1 indicates that dissociating a $\mathrm{C}-\mathrm{H}$ bond of $\mathrm{BZ}$, either from a $\mathrm{C}$ atom on top of a $\mathrm{Ni}$ atom or from a $\mathrm{C}$ atom bridging two $\mathrm{Ni}$ atoms, is a highly endothermic process, consistent with the literature. ${ }^{39}$ Nevertheless, the dissociation energy, $E_{\text {diss, }}$ of a $\mathrm{C}-\mathrm{H}$ bond from a $\mathrm{C}$ atom on top of a $\mathrm{Ni}$ atom, $0.89 \mathrm{eV}$, is remarkably lower than the $E_{\text {diss }}$ of a $\mathrm{C}-\mathrm{H}$ bond from a $\mathrm{C}$ atom bridging two $\mathrm{Ni}$ atoms, $1.34 \mathrm{eV}$. Focusing on geometry, dissociation of a $\mathrm{C}-\mathrm{H}$ bond from a $\mathrm{C}$ atom on top a $\mathrm{Ni}$ atom results in a shortening of the distance between the $\mathrm{C}$ atom and the $\mathrm{Ni}$ atom on the surface to $1.87 \AA$ (Figure 5 ). The $\mathrm{BZ}$ ring still is parallel to the $\mathrm{Ni}$ surface, although the $\mathrm{C}$ involved in the dissociation of the $\mathrm{C}-\mathrm{H}$ bond is clearly pulled toward the $\mathrm{Ni}$ atom to maximize interaction between the $\mathrm{sp}^{2}$ orbital of BZ, previously involved in the $\mathrm{C}-\mathrm{H}$ bond, with the $\mathrm{Ni}$ atom on the surface. In the case of dissociation of a $\mathrm{C}-\mathrm{H}$ bond from a $\mathrm{C}$ atom bridging two $\mathrm{Ni}$ atoms, the $\mathrm{BZ}$ ring is clearly tilted, with the $\mathrm{C}$ atom involved in long bonds with two $\mathrm{Ni}$ atoms on the surface, and the para $\mathrm{C}$ atom more than $2.5 \AA$ away from the nearest $\mathrm{Ni}$ atom (Figure 5). In both cases, the dissociated $\mathrm{H}$ atom is placed in a hollow site. These geometrical
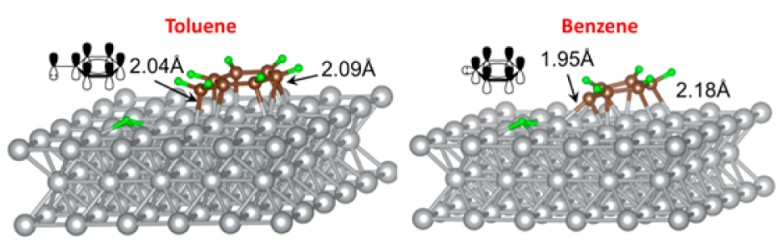

Figure 5. Optimized geometries resulting from dissociation of a first $\mathrm{C}-\mathrm{H}$ bond of TOL and BZ.

differences are evidence of a stronger $\mathrm{Ni}-\mathrm{C} \sigma$-bond and a stronger interaction between the aromatic ring and the $\mathrm{Ni}$ surface when $\mathrm{C}-\mathrm{H}$ dissociation occurs from a $\mathrm{C}$ atom on top of a $\mathrm{Ni}$ atom, and explain the remarkably lower $E_{\text {diss. }}$ For this reason, in the case of TOL we only focused on the dissociation of aromatic $\mathrm{C}-\mathrm{H}$ bonds from $\mathrm{C}$ atoms on top of a $\mathrm{Ni}$ atom.

Moving to TOL, dissociation of an aromatic $\mathrm{C}-\mathrm{H}$ bond of TOL is again endothermic, with $E_{\text {diss }}$ in the $0.8-0.9 \mathrm{eV}$ range, which is close to what was calculated for dissociation of a $\mathrm{C}-\mathrm{H}$ bond on top of a $\mathrm{Ni}$ atom in case of BZ. No meaningful difference is calculated between the $\mathrm{C}-\mathrm{H}$ bonds ortho, meta and para to the TOL methyl group. In contrast, dissociation of a $\mathrm{C}-\mathrm{H}$ bond of the methyl group is clearly exothermic, with an $E_{\text {diss }}$ of $-0.61 \mathrm{eV}$ (Table 1). Analysis of the geometry after C$\mathrm{H}$ dissociation from the methyl group reveal that removal of a $\mathrm{H}$ atom results in the formation of an exocyclic $\mathrm{CH}_{2}=\mathrm{C}$ bond that is strongly conjugated with the aromatic ring (Figure 5). This is evidenced by the decrease in the length of the exocyclic $\mathrm{C}-\mathrm{C}$ bond from $1.51 \AA$ in adsorbed TOL to $1.47 \AA$ after $\mathrm{C}-\mathrm{H}$ dissociation, and by the almost in-plane geometry of the exocyclic $\mathrm{C}-\mathrm{C}$ bond, with a $\mathrm{C}_{\text {para }}-\mathrm{C}_{\text {ipso }}-\mathrm{C}_{\text {exocylic }}$ angle of $179^{\circ}$, versus $159^{\circ}$ in the adsorbed TOL, comparing Figures 4 and 5. Further, the exocyclic $\mathrm{C}$ atom of TOL after $\mathrm{C}-\mathrm{H}$ dissociation strongly interacts with the surface, with a distance from the closest $\mathrm{Ni}$ atom of only $2.04 \AA$, versus a distance of $3.21 \AA$ in the adsorbed TOL. The enhanced interaction of TOL with the $\mathrm{Ni}$ surface after $\mathrm{C}-\mathrm{H}$ dissociation explains the exothermic character of the first $\mathrm{C}-\mathrm{H}$ dissociation for TOL. Incidentally, dissociation from a methyl group bound to a $\mathrm{C}$ atom on top of a $\mathrm{Ni}$ atom is slightly favored, by $0.07 \mathrm{eV}$, relative to $\mathrm{C}-\mathrm{H}$ dissociation from a $\mathrm{C}$ atom bridging two $\mathrm{Ni}$ atoms. At this point, we located the transition state for dissociation of a $\mathrm{C}-\mathrm{H}$ bond of the methyl group of TOL. According to calculations, the $\mathrm{C}-\mathrm{H}$ bond, $1.53 \AA$, is almost completely broken at the transition state, with a calculated activation barrier of $0.68 \mathrm{eV}$, see Figure S5. This rather low activation barrier for $\mathrm{C}-\mathrm{H}$ dissociation from the methyl group of TOL corresponds to a barrier of $1.29 \mathrm{eV}$ for the reverse reaction, which is hydrogenation of adsorbed $\mathrm{C}_{6} \mathrm{H}_{5} \mathrm{CH}_{2}$ to TOL. Barriers of this magnitude are consistent with rapid kinetics at the experimentally used temperature of $300-360{ }^{\circ} \mathrm{C}$.

The dissociation of the second $\mathrm{C}-\mathrm{H}$ bond is again endothermic for the case of $\mathrm{BZ}$, and it involves a $\mathrm{C}-\mathrm{H}$ bond ortho to the first $\mathrm{C}-\mathrm{H}$ bond, see Figure $\mathrm{S} 6$, with a $E_{\text {diss }}$ of 0.55 $\mathrm{eV}$. Dissociation of the $\mathrm{C}-\mathrm{H}$ bonds meta and para to the first $\mathrm{C}-\mathrm{H}$ bond is calculated to be 0.17 and $0.21 \mathrm{eV}$ more endothermic. For TOL, dissociation of a second $\mathrm{C}-\mathrm{H}$ bond involves again the exocyclic $\mathrm{C}$ atom, and it is endothermic by $1.02 \mathrm{eV}$. Dissociation of the aromatic $\mathrm{C}-\mathrm{H}$ bonds are more than $0.25 \mathrm{eV}$ higher in energy (Table 1 ).

The easier $\mathrm{C}-\mathrm{H}$ dissociation of TOL compared to $\mathrm{BZ}$, -0.61 versus $0.89 \mathrm{eV}$, for a difference of $1.50 \mathrm{eV}$, can be decomposed into two main factors. The first is the intrinsic 
weakness of the $\mathrm{C}-\mathrm{H}$ bonds of the methyl group of TOL compared to the $\mathrm{C}-\mathrm{H}$ bonds of $\mathrm{BZ}$. Indeed, the homolytic dissociation of these bonds in the gas phase is predicted to be $0.97 \mathrm{eV}$ easier in TOL. The second is the better interaction between the $\mathrm{C}_{6} \mathrm{H}_{5}-\mathrm{CH}_{2}$ fragment of TOL and the Ni surface compared to the interaction between the $\mathrm{C}_{6} \mathrm{H}_{5}$ fragment of $\mathrm{BZ}$ and the surface. The $\mathrm{CH}_{2}$ group of the former can assume a sp ${ }^{2}$ geometry, with the $\mathrm{p}$ orbital on the $\mathrm{C}$ atom conjugated with the aromatic ring and well oriented to interact with the surface (Figure 5). In contrast, $\mathrm{C}-\mathrm{H}$ dissociation from $\mathrm{BZ}$ occurs from a sp2 orbital in the ring plane, which is not properly oriented to interact with the surface, resulting in the strong geometric distortion of the $\mathrm{C}_{6} \mathrm{H}_{5}$ moiety that can be noted in Figure 5 .

Overall, the first $\mathrm{C}-\mathrm{H}$ bond dissociation energy of $\mathrm{BZ}$ is clearly an endothermic process, which indicates that $\mathrm{BZ}$ has a tendency to remain intact after dehydrogenation of $\mathrm{CH}$. Distinctively, the first $\mathrm{C}-\mathrm{H}$ bond dissociation energy of TOL is clearly an exothermic process, which indicates that dehydrogenation of MCH does not stop at the TOL structure, but there is a thermodynamic driving force to dehydrogenate further to an adsorbed $\mathrm{C}_{6} \mathrm{H}_{5}=\mathrm{CH}_{2}$. This dehydrogenated TOL structure was indeed found during thermal decomposition experiment using isotopic labeling, as reported in the literature. ${ }^{39}$ In this scheme, the stronger dependence of $\mathrm{H}_{2}$ pressure for $\mathrm{MCH}$ dehydrogenation than for $\mathrm{CH}$ dehydrogenation can be rationalized, considering that a high pressure of $\mathrm{H}_{2}$ can promote $\mathrm{C}_{6} \mathrm{H}_{5}=\mathrm{CH}_{2}$ hydrogenation to TOL.

Postulated Reaction Mechanisms. Based on the discussion above, elementary steps can be derived as follows. The reaction mechanism is consistent with the one proposed for hydrocarbon reforming catalysts, such as ethane hydrogenolysis in excess $\mathrm{H}_{2}{ }^{43} \mathrm{H}_{2}$ is reversibly and dissociatively adsorb on the sites $\otimes$ which are different from those required for $\mathrm{MCH}$ or TOL adsorption, *.

$$
2 \otimes+\mathrm{H}_{2} \stackrel{k_{1}}{\rightleftharpoons} 2 \mathrm{H} \otimes
$$

$\mathrm{MCH}$ is chemisorbed on $\mathrm{Ni}$ by producing adsorbed $\mathrm{H}$ (including one from the methyl group), which are either bound on $\otimes$ or released as $\mathrm{H}_{2}$.

$$
\begin{aligned}
& \mathrm{C}_{6} \mathrm{H}_{11} \mathrm{CH}_{3}+*+n \otimes \\
& \stackrel{k_{2}}{\rightarrow} \mathrm{C}_{6} \mathrm{H}_{5} \mathrm{CH}_{2}^{*}+n(\mathrm{H} \otimes)+\frac{7-n}{2} \mathrm{H}_{2}
\end{aligned}
$$

Here, these elementary steps should occur, suggesting that these $\otimes$ sites (such as the Ni hollow site) should exist adjacent to $*$ sites ( such as the site atop $\mathrm{Ni}$ ), see Figure 5 . The hydrogenation of strongly absorbed species, namely, $\mathrm{C}_{6} \mathrm{H}_{5} \mathrm{CH}_{2} *$ gives

$$
\mathrm{C}_{6} \mathrm{H}_{5} \mathrm{CH}_{2} *+a \mathrm{H}_{2} \stackrel{k_{3}}{\rightarrow} \mathrm{C}_{6} \mathrm{H}_{5} \mathrm{CH}_{3} *
$$

Then, adsorbed TOL desorbs:

$$
\mathrm{C}_{6} \mathrm{H}_{5} \mathrm{CH}_{3} * \stackrel{k_{4}}{\rightarrow} \mathrm{C}_{6} \mathrm{H}_{5} \mathrm{CH}_{3}+*
$$

Because reaction 3 is the rate-determining step, it then provides:

$$
\text { TOF }=k_{3}\left[\mathrm{C}_{6} \mathrm{H}_{11} \mathrm{CH}_{2} *\right]\left[\mathrm{H}_{2}\right]^{a}
$$

To simplify, using the quasi-equilibrated step (1) and $\mathrm{H} \otimes$ and $\mathrm{C}_{6} \mathrm{H}_{5} \mathrm{CH}_{2} *$ as the most abundant surface intermediates, respectively, gives

$$
\mathrm{TOF}=k_{3}\left[\mathrm{H}_{2}\right]^{a}
$$

This rate expression is consistent with negligible $\mathrm{MCH}$ dependence, and positive order in $\mathrm{H}_{2}$. When the hydrogenation capability of the catalyst is facile, reaction 4 becomes ratedetermining:

$$
\mathrm{TOF}=k_{4}
$$

This desorption-limiting rate expression is consistent with zero-order pressure dependences for both reactants $(\mathrm{MCH}$ or $\mathrm{CH}$, and $\mathrm{H}_{2}$ ), prevalent for the Pt catalysts. This desorptionlimiting mechanism is well documented in the literature for $\mathrm{Pt}$ catalysts (further details are described in Supporting Information). ${ }^{43}$ The essential role of the presence of excess $\mathrm{H}_{2}$ to stabilize the catalytic performance even for Pt catalysts implies that the hydrogenation step shown in reaction 3 still occurs on Pt, but it is kinetically irrelevant. Therefore, it is anticipated that the main difference between $\mathrm{Pt}$ and $\mathrm{Ni}$ may arise from their hydrogenation capability, which are additionally associated with $\pi$ bond-conjugated aromatics on the surface.

The apparent activation energies for three catalysts were measured using $10 \mathrm{kPa} \mathrm{MCH}$ or $\mathrm{CH}$ and $30 \mathrm{kPa} \mathrm{H}_{2}$ in the temperature range of $300-360{ }^{\circ} \mathrm{C}$. The results are compiled in Table 2. For all the catalysts, the activation energy for $\mathrm{CH}$

Table 2. Measured Activation Energy for $\mathrm{MCH}$ and $\mathrm{CH}$ Dehydrogenation (20 mg-cat, $10 \mathrm{kPa} \mathrm{MCH}$ or $\mathrm{CH}, 30 \mathrm{kPa}$ $\left.\mathrm{H}_{2}, 3.3 \times 10^{6} \mathrm{~g} \mathrm{~h} \mathrm{~mL}^{-1}, 300-360^{\circ} \mathrm{C}\right)$

\begin{tabular}{ccc} 
& \multicolumn{2}{c}{$E_{\mathrm{a}}\left(\mathrm{kJ} \mathrm{mol}^{-1}\right)$} \\
\cline { 2 - 3 } catalyst & $\mathrm{MCH}$ & $\mathrm{CH}$ \\
$\mathrm{Pt} / \mathrm{Al}_{2} \mathrm{O}_{3}$ & $59( \pm 6)$ & $45( \pm 5)$ \\
$\mathrm{Ni} / \mathrm{Al}_{2} \mathrm{O}_{3}$ & $72( \pm 7)$ & $44( \pm 4)$ \\
$\mathrm{NiZn} / \mathrm{Al}_{2} \mathrm{O}_{3}$ & $80( \pm 8)$ & $57( \pm 6)$ \\
\hline
\end{tabular}

dehydrogenation is lower than that for $\mathrm{MCH}$ dehydrogenation. For $\mathrm{MCH}$ conversion, a slightly lower activation energy of 59 $\mathrm{kJ} \mathrm{mol}{ }^{-1}$ was obtained for Pt catalyst, consistent with the literature, ${ }^{36,37,44}$ than for $\mathrm{Ni}$ and NiZn catalysts $(72$ and $80 \mathrm{~kJ}$ $\mathrm{mol}^{-1}$, respectively). The difference may originate from the different rate-determining steps when using the Pt- and Nibased catalysts: reaction 4 for $\mathrm{Pt}$, and reaction 3 for Ni-based catalysts, as discussed previously. For the rate expressed in the form of eq 6 ( $\mathrm{Ni}$ and $\mathrm{NiZn}$ catalysts), the apparent activation energy $\left(E_{\mathrm{a} \text {,app }}\right)$ is the sum of the heat of adsorption of $\mathrm{H}_{2}$ according to $(1)\left(\Delta H_{\mathrm{H}}\right)$ and the activation energy for reaction $3\left(E_{\mathrm{a}, 3}\right)$ (i.e., $\left.E_{\mathrm{a}, \mathrm{app}}=\Delta H_{\mathrm{H}}+E_{\mathrm{a}, 3}\right)$. For the rate expressed in the form of eq 7, the activation energy should resemble the value of heat of desorption of TOL $\left(\Delta H_{\mathrm{TOL}}\right)$. For $\mathrm{CH}$ conversion, the activation energies of $\mathrm{Pt}$ and $\mathrm{Ni}$ catalysts are comparable (44$45 \mathrm{~kJ} \mathrm{~mol}^{-1}$ ), and that of NiZn catalyst was slightly higher (57 $\left.\mathrm{kJ} \mathrm{mol}^{-1}\right)$. Nearly zero-order kinetics in both reactants $(\mathrm{CH}$ and $\left.\mathrm{H}_{2}\right)$ suggest that desorption of $\mathrm{BZ}\left(\Delta \mathrm{H}_{\mathrm{BZ}}\right)$ may be kinetically relevant, similar to the discussion for $\mathrm{MCH}$ conversion above. It is noted that the activation energy may significantly differ because of different temperature range, partial pressures of reactant and $\mathrm{H}_{2}$, and associated surface coverages. It should be possible for the rate-determining step to even switch, for example, between reaction 3 and 4, by changing such reaction parameters and catalysts, resulting in distinctive activation energy values.

So far, this study noted the impact of the alkyl functional group in the aromatic compounds. It is reasonable to consider 
that there should be a general trend that the strong contribution of alkyl species on the aromatic ring drastically enhance the heat of adsorption by producing dehydrogenated compounds on the surface. This finding may be translated for general reforming and hydrogenolysis catalysis using this type of catalyst. Next, the electronic and geometric structures of $\mathrm{Ni}$ based sample will be discussed.

Impact of $\mathrm{Zn}$ on the Electronic and Geometric Structure of $\mathrm{Ni}$. $\mathrm{Zn}$ addition to a $\mathrm{Ni}$ catalyst improved the selectivity of $\mathrm{MCH}$ to TOL. We postulated in our previous communication that the $\mathrm{Zn}$ substitutes on the edge site of $\mathrm{Ni}$. The edge site of $\mathrm{Ni}$ facilitates $\mathrm{C}-\mathrm{C}$ cracking. ${ }^{13}$ In situ X-ray absorption study in the literature clearly demonstrated that the $\alpha$-NiZn alloy was formed from $\mathrm{NiO} / \mathrm{ZnO}$ by $\mathrm{H}_{2}$ treatment at $400{ }^{\circ} \mathrm{C} .{ }^{45}$ In this study, characterization of $\mathrm{Zn}$ and DFT calculation were used to address the electronic and geometric structure to identify the impact of NiZn bimetallic catalysts for improving the selectivity.

First, Figure 6 shows STEM analysis for the bimetallic NiZn catalysts. The bright dots correspond to the metal particles in

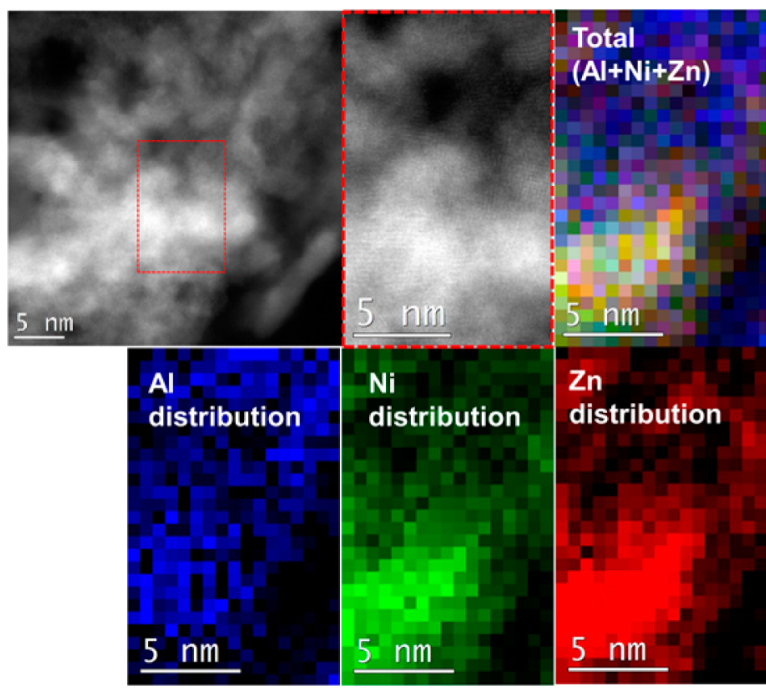

Figure 6. STEM image and corresponding elemental mapping by EELS for the $\mathrm{NiZn} / \mathrm{Al}_{2} \mathrm{O}_{3}$ catalyst after $24 \mathrm{~h} \mathrm{MCH}$ dehydrogenation reaction $\left(300{ }^{\circ} \mathrm{C}, 10 \mathrm{kPa} \mathrm{MCH}, 30 \mathrm{kPa} \mathrm{H}_{2}\right)$.

the STEM mode in all of the catalysts. The distribution of these bimetallic nanoparticles were measured and found to be almost identical (approximately 2-5 nm), irrespective of the sample, and this means there was no apparent differences between the fresh and spent catalysts. This may suggest that the catalysts are still catalytically active toward $\mathrm{MCH}$ dehydrogenation. EELS elemental mapping shown in Figures 6 and S7 exhibits that the positions of $\mathrm{Ni}$ and $\mathrm{Zn}$ well overlap in the nm-range. XRD was also carried out on the spent catalysts to determine any change in crystal/particle size after the catalytic testing. The position of peaks of all the catalysts are found to be comparable. Consistent with the small particle size obtained from the STEM images (Figure 6), the metallic (or alloy) peaks of both catalysts were not clearly visible and overlapped with the peaks of the $\gamma-\mathrm{Al}_{2} \mathrm{O}_{3}$ support as reported. ${ }^{13}$

The electronic structure of the NiZn alloy was investigated by DFT calculation. The density of states (DOS) of $\mathrm{Ni} / \mathrm{Zn}$ alloys were calculated for the catalysts consisting of $\mathrm{Ni} / \mathrm{Zn}$ compositions of $100 / 0,75 / 25,50 / 50,25 / 75$, and $0 / 100$, using special quasirandom structures (SQS) from literature. ${ }^{32}$ Analysis of the total and projected DOS for the various structures (Figure 7 and Figure S8) indicates that the $\mathrm{d}$ band of

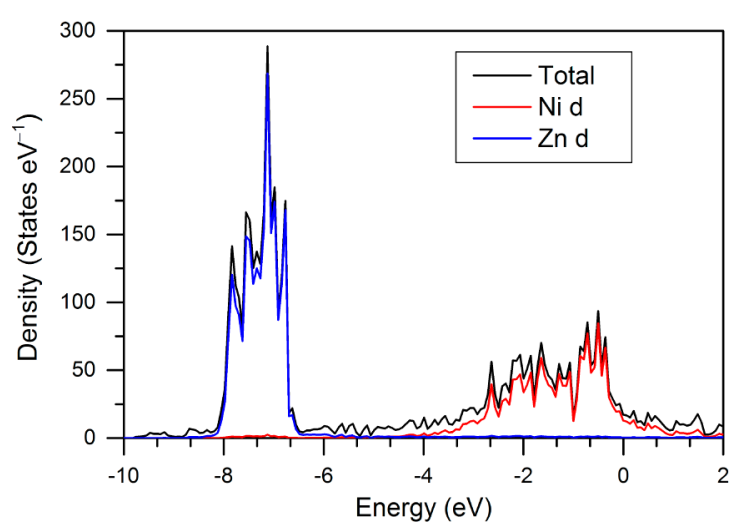

Figure 7. Total and projected DOS for a $50 / 50 \mathrm{Ni} / \mathrm{Zn}$ alloy.

pure $\mathrm{Ni}$ and $\mathrm{Zn}$ is centered at sharply different energies, -7.69 and $-1.56 \mathrm{eV}$, respectively. In addition, the width of these $\mathrm{d}$ bands is approximately 4 and $1.5 \mathrm{eV}$, respectively. This prevents their hybridization, resulting in two well-separated $\mathrm{Ni}$ and $\mathrm{Zn} \mathrm{d}$ bands in the three considered alloys (see Figure 7 reporting the DOS of the 50/50 alloy). Nevertheless, alloying results in a narrowing of the d-band of $\mathrm{Ni}$ by almost $1 \mathrm{eV}$ and in a $0.15 \mathrm{eV}$ shift of the d-band center of $\mathrm{Ni}$ from $-1.56 \mathrm{eV}$ in pure $\mathrm{Ni}$ to $-1.41 \mathrm{eV}$ in the $50 / 50$ alloy.

To understand the preference of $\mathrm{Zn}$ to be embedded in the bulk or at the surface of a regular Ni structure, we recall briefly calculations we performed on a cluster model consisting of 55 $\mathrm{Ni}$ atoms in an NP with icosahedron geometry. ${ }^{13}$ Specifically, we modeled $\mathrm{Ni}_{54} \mathrm{Zn}$ NPs, with the $\mathrm{Zn}$ atom replacing a single $\mathrm{Ni}$ atom at one of the four unique symmetry positions of an icosahedron $\mathrm{Ni}_{55} \mathrm{NP}$. Our calculations indicated that substitution of a $\mathrm{Ni}$ atom by a $\mathrm{Zn}$ atom occurs preferentially at one of the 12 equivalent corners of the second shell around the central atom, with substitution of a $\mathrm{Ni}$ atom in the central position of one of the 20 equivalent edges of the second shell around the central atom only $0.01 \mathrm{eV}$ higher in energy. Clearly, a higher energy was calculated when substitution of a $\mathrm{Ni}$ atom occurs at one of the 12 equivalent positions in the first shell around the central atom, $1.63 \mathrm{eV}$, or at the center (the core) of the nanoparticle, $1.51 \mathrm{eV}{ }^{13}$ Further, in the same work, we also calculated the substitution energy in the regular (100), (111), and (211) Ni surfaces. According to the calculations, the geometry of lowest energy corresponds to substitution of one $\mathrm{Ni}$ atom by a $\mathrm{Zn}$ atom at the top of the step of the (211) surface, followed by substitution of one $\mathrm{Ni}$ atom of the (100) surface, $0.11 \mathrm{eV}$ higher in energy. ${ }^{13}$ Close in energy is substitution of a $\mathrm{Ni}$ atom at the middle position of the step on the (211) surface or at the (111) surface, 0.11 and $0.18 \mathrm{eV}$ higher in energy, respectively. Substitution of a $\mathrm{Ni}$ atom at the bottom of the step on the (211) surface is at clearly higher energy, $0.41 \mathrm{eV} .^{13}$

To extend the conclusions derived on single Ni substitution in $\mathrm{Ni}_{55} \mathrm{NPs}$ or regular $\mathrm{Ni}$ surfaces to larger systems, with a higher Zn content, we performed a comprehensive search for stable configurations when $n \mathrm{Ni}$ atoms are replaced by $\mathrm{n} \mathrm{Zn}$ atoms in Ni nanoparticles. We considered the cluster expansion (CE) method to replace $\mathrm{Ni}$ by $\mathrm{Zn}$ atoms up to a $\mathrm{Zn}$ concentration of $50 \%$ in a $\mathrm{Ni}_{147}$ nanoparticle. Within the $\mathrm{CE}$ 
approach, the $n \mathrm{Ni}$ atoms are substituted one by one. Each time a new atom $\mathrm{Zn}$ atom is added, substitution of all the $\mathrm{Ni}$ atoms is tested and only the geometry giving the lowest energy is kept for addition of further $\mathrm{Zn}$ atoms. Consistently with the results on the $\mathrm{Ni}_{54} \mathrm{Zn} \mathrm{NP}$, the first $\mathrm{Zn}$ atom is placed at the surface of the $\mathrm{Ni}_{147}$ nanoparticle, with a small preference $(0.01 \mathrm{eV})$ for one of the corners. Up to $12 \mathrm{Zn}$ atoms substitution occurs at the 12 corners of the Ni nanoparticle, see Figure 8.
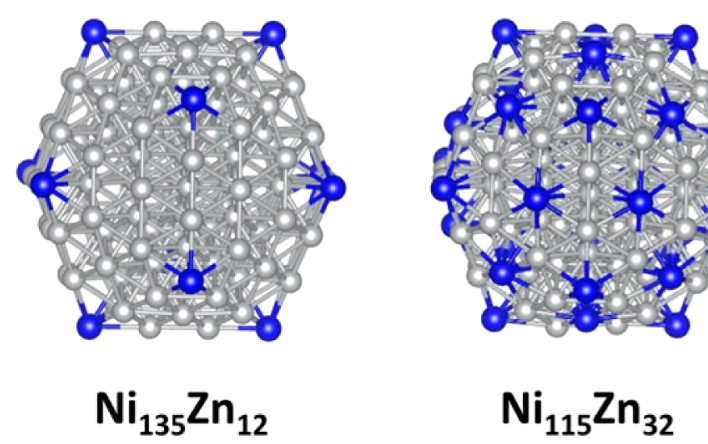

Figure 8. Lowest-energy structures of 147 atoms NiZn NP with different $\mathrm{Zn}$ concentrations. $\mathrm{Ni}$ in gray, $\mathrm{Zn}$ in blue.

For higher concentration of $\mathrm{Zn}$ (more than 12 atoms), substitution of $\mathrm{Ni}$ atoms preferentially occurs at the center of the facets, until the 20 facets are filled in the $\mathrm{Ni}_{115} \mathrm{Zn}_{32} \mathrm{NP}$, see Figure 8. This is consistent with the conclusion on the $\mathrm{Ni}_{55} \mathrm{NP}$ that $\mathrm{Ni}$ substitution by $\mathrm{Zn}$ occurs preferentially on the surface of the NP. However, it is worth noting that the $\mathrm{Ni}_{115} \mathrm{Zn}_{32} \mathrm{NP}$ shows no $\mathrm{Zn}$ atom along the edge, despite calculations on the $\mathrm{Ni}_{54} \mathrm{Zn}$ NP that indicated a minimal energy difference between geometries presenting the $\mathrm{Zn}$ atom on the corner or on the edge. Considering that adding a $\mathrm{Zn}$ atom on one of the edges of the $\mathrm{Ni}_{115} \mathrm{Zn}_{12} \mathrm{NP}$ of Figure 8 would lead to the formation of a $\mathrm{Zn}-\mathrm{Zn}$ bond, this suggests that geometries with two vicinal $\mathrm{Zn}$ atoms, thus forming a $\mathrm{Zn}-\mathrm{Zn}$ bond, are disfavored relative to geometries presenting $\mathrm{Ni}-\mathrm{Zn}$ bonds only. To test this hypothesis, we calculated three possible geometries for the $\mathrm{Ni}_{145} \mathrm{Zn}_{2} \mathrm{NP}$, presenting one $\mathrm{Zn}$ at one of the corners, and the second $\mathrm{Zn}$ either at (i) another corner, (ii) at the center of the facet, or (iii) along one of the edges and forming a $\mathrm{Zn}-\mathrm{Zn}$ bond with the $\mathrm{Zn}$ atom at the corner. In contrast, the first two geometries do not present any $\mathrm{Zn}-\mathrm{Zn}$ bonds. According to calculations, the geometry with the two $\mathrm{Zn}$ atoms at the corner is the most stable, followed by the geometry with the second $\mathrm{Zn}$ atom at the center of the facet, $0.21 \mathrm{eV}$ higher in energy, and finally by the geometry presenting the second atom along the edge, thus forming a $\mathrm{Zn}-\mathrm{Zn}$ bond, which is a further 0.04 $\mathrm{eV}$ higher in energy. This indicates that the energy penalty required to form a $\mathrm{Zn}-\mathrm{Zn}$ bond is severe enough to push $\mathrm{Zn}$ atoms to the center of the facets, despite the edges being intrinsically more stable. Consistent with these considerations, further increasing the $\mathrm{Zn}$ concentration (more than 32 atoms) results in geometries presenting $\mathrm{Zn}$ atoms also in the inner shells.

Concluding this part, our analysis of $\mathrm{Ni} / \mathrm{Zn} \mathrm{NPs}$ and slabs converge on the point that $\mathrm{Ni}$ substitution by $\mathrm{Zn}$ occurs preferentially at low-coordinated $\mathrm{Ni}$ atoms at the surface of the NP or slab, such as corners or edges of the NPs, and atoms at the top of the step on the (211) surface. This conclusion can be reasonably extended to include any defect on the (100) and (111) surfaces resulting in low coordination at the $\mathrm{Ni}$ atom.
Furthermore, our calculations indicated that formation of $\mathrm{Zn}-$ $\mathrm{Zn}$ bonds is unfavored relative to dispersion of the $\mathrm{Zn}$ atoms in the Ni matrix, with formation of only $\mathrm{Ni}-\mathrm{Zn}$ bonds. Overall, these conclusions can be related to the larger radius of $\mathrm{Zn}$ relative to $\mathrm{Ni}, 1.34$ versus $1.24 \AA$, respectively, which prevents easily accommodating $\mathrm{Zn}$ into the regular fcc structure of $\mathrm{Ni}$.

At this point, we examined the possible pathways connected to the dissociation of the exocyclic $\mathrm{C}-\mathrm{C}$ bond of TOL. Dissociation of this bond leads to the formation of a $\mathrm{C}_{6} \mathrm{H}_{5}$ moiety. Analysis of this structure already revealed strong deformation of the aromatic ring to have the $\mathrm{sp}^{2}$ orbital formerly involved in the $\mathrm{C}-\mathrm{C}$ bond interacting with the flat $\mathrm{Ni}$ surface (see Figure 5). At this point, we reasoned that any surface defect, such as adatoms, kinks, or steps, could facilitate $\mathrm{C}-\mathrm{C}$ dissociation by stabilizing adsorption of the $\mathrm{C}_{6} \mathrm{H}_{5}$ moiety, as illustrated in Figure 9. Indeed, using the step model of Figure

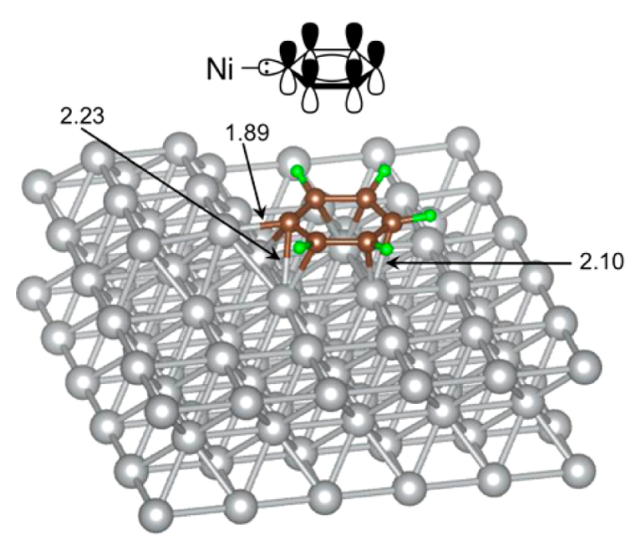

Figure 9. Optimized geometry for $\mathrm{C}_{6} \mathrm{H}_{5}$ adsorption on a defected $\mathrm{Ni}(100)$ surface.

9 as a prototypical case, adsorption of the $\mathrm{C}_{6} \mathrm{H}_{5}$ moiety is favored by $0.23 \mathrm{eV}$ relative to adsorption of the $\mathrm{C}_{6} \mathrm{H}_{5}$ moiety on the flat surface (Figure 5). Comparison of the structures in Figures 5 and 9 show a much less distorted structure if the $\mathrm{C}_{6} \mathrm{H}_{5}$ moiety can engage in a $\mathrm{Ni}-\mathrm{C}$ bond in plane with the aromatic ring. Of course, the same reasoning can be applied to dissociation of a $\mathrm{C}-\mathrm{H}$ bond of $\mathrm{BZ}$. As expected, lowcoordinated sites of $\mathrm{Ni}$ are preferentially occupied by $\mathrm{Zn}$, as confirmed by DFT calculation. The $\mathrm{Zn}$ occupation on the corner site is $0.17 \mathrm{eV}$ more preferred compared to that on a flat surface (the geometry of the surface is shown in Figure S9). It is likely that the impact of $\mathrm{Zn}$ alloying is geometric site occupation of low-coordination sites of $\mathrm{Ni}$ with inert $\mathrm{Zn}$ atoms, which prevents the unpreferred methanation. As a result, NiZn shows improved selectivity for TOL over monometallic $\mathrm{Ni}$ catalyst.

\section{CONCLUSIONS}

The kinetic analysis of $\mathrm{MCH}$ dehydrogenation reaction revealed a fractional order with respect to $\mathrm{MCH}$ for the three catalysts. In contrast, an approximately half order with respective to $\mathrm{H}_{2}$ was observed for $\mathrm{NiZn}$ and $\mathrm{Ni}$ catalysts, differing from the nearly zero order for Pt catalyst. DFT calculation indicated that exothermic dissociative adsorption of TOL occurs, losing a $\mathrm{H}$ from the methyl functional group. This strongly adsorbed surface intermediate led to the kinetics where hydrogenation is paradoxically the rate-determining step during dehydrogenation of $\mathrm{MCH}$. This mechanism explains the 
essential role played by $\mathrm{H}_{2}$ in maintaining the activity of the metallic surface from the $\mathrm{H}$-deficient surface species produced via the dehydrogenation of TOL. In contrast, sensitivity to the $\mathrm{H}_{2}$ pressure was smaller in the absence of methyl group (i.e., $\mathrm{CH}$ dehydrogenation to $\mathrm{BZ}$ ). DFT calculation suggested that low-coordinated $\mathrm{Ni}$ step sites were responsible for $\mathrm{C}-\mathrm{C}$ cracking of the methyl group from aromatics as the H-deficient BZ was stabilized at such sites. A combined experimental and theoretical study led to the hypothesis that $\mathrm{Zn}$ preferentially occupies these low-coordinated unselective sites (such as corner and edge sites), which in turn avoids the $\mathrm{C}-\mathrm{C}$ cracking and is thus responsible for the improved TOL selectivity. The effects of the alloy and the reaction mechanism presented in this study can be generalized for various alkyl aromatic chemistries, which are relevant to various catalytic reforming/ hydrogenation/dehydrogenation/hydrogenolysis reactions.

\section{ASSOCIATED CONTENT}

\section{S Supporting Information}

The Supporting Information is available free of charge on the ACS Publications website at DOI: 10.1021/acscatal.6b03299.

Catalyst preparation, thermodynamic aspects of relevant dehydrogenation reactions, catalyst characterization, supplementary kinetic data, and theoretical data (PDF)

\section{AUTHOR INFORMATION}

\section{Corresponding Authors}

*E-mail: kazuhiro.takanabe@kaust.edu.sa.

*E-mail: luigi.cavallo@kaust.edu.sa.

ORCID ${ }^{\circ}$

Abdesslem Jedidi: 0000-0003-4070-3299

Luigi Cavallo: 0000-0002-1398-338X

Kazuhiro Takanabe: 0000-0001-5374-9451

Notes

The authors declare no competing financial interest.

\section{ACKNOWLEDGMENTS}

Research reported in this work was supported by the King Abdullah University of Science and Technology (KAUST). A.A. acknowledges Saudi Aramco for financial support. A.J. and L.C. are grateful to the KAUST Supercomputing Laboratory (KSL) for the resources provided under the project k1087

\section{REFERENCES}

(1) Schlapbach, L.; Züttel, A. Nature 2001, 414, 353-358.

(2) Johnston, B.; Mayo, M. C.; Khare, A. Technovation 2005, 25, 569-585.

(3) Sartbaeva, A.; Kuznetsov, V. L.; Wells, S. A.; Edwards, P. P. Energy Environ. Sci. 2008, 1, 79-85.

(4) Ball, M.; Wietschel, M. Int. J. Hydrogen Energy 2009, 34, 615627.

(5) Zegers, P. J. Power Sources 2006, 154, 497-502.

(6) Edwards, P. P.; Kuznetsov, V. L.; David, W. I. F.; Brandon, N. P. Energy Policy 2008, 36, 4356-4362.

(7) Scherer, G. W. H.; Newson, E.; Wokaun, A. Int. J. Hydrogen Energy 1999, 24, 1157-1169.

(8) Newson, E.; Haueter, T.; Hottinger, P.; Von Roth, F.; Scherer, G. W. H.; Schucan, Th. H. Int. J. Hydrogen Energy 1998, 23, 905-909.

(9) DeLuchi, M. A. Int. J. Hydrogen Energy 1989, 14, 81-130.

(10) Okada, Y.; Sasaki, E.; Watanabe, E.; Hyodo, S.; Nishijima, H. Int. J. Hydrogen Energy 2006, 31, 1348-1356.

(11) Biniwale, R. B.; Rayalu, S.; Devotta, S.; Ichikawa, M. Int. J. Hydrogen Energy 2008, 33, 360-365.
(12) Zhu, Q. L.; Xu, Q. Energy Environ. Sci. 2015, 8, 478-512.

(13) Al-ShaikhAli, A. H.; Jedidi, A.; Cavallo, L.; Takanabe, K. Chem. Commun. 2015, 51, 12931-12934.

(14) Studt, F.; Abild-Pedersen, F.; Bligaard, T.; Sørensen, R. Z.; Christensen, C. H.; Nørskov, J. K. Science 2008, 320, 1320-1322.

(15) Desai, P. H.; Richardson, J. T. J. Catal. 1986, 98, 392-400.

(16) Rodríguez, J. C.; Marchi, A. J.; Borgna, A.; Monzón, A. J. Catal. 1997, 171, 268-278.

(17) Vang, R. T.; Honkala, K.; Dahl, S.; Vestergaard, E. K.; Schnadt, J.; Laegsgaard, E.; Clausen, B. S.; Nørskov, J. K.; Besenbacher, F. Nat. Mater. 2005, 4, 160-162.

(18) Spanjers, C. S.; Held, J. T.; Jones, M. J.; Stanley, D. D.; Sim, R. S.; Janik, M. J.; Rioux, R. M. J. Catal. 2014, 316, 164-173.

(19) Viswanathan, V. N.; Yeddanapalli, L. M. Z. Anorg. Allg. Chem. 1974, 407, 62-74.

(20) Al-Ayed, O. S.; Kunzru, D. J. Chem. Technol. Biotechnol. 1988, $43,23-38$.

(21) Biniwale, R. B.; Kariya, N.; Ichikawa, M. Catal. Lett. 2005, 105, 83-87.

(22) Yolcular, S.; Olgun, Ö. Catal. Today 2008, 138, 198-202.

(23) Kresse, G.; Furthmüller, J. Phys. Rev. B: Condens. Matter Mater. Phys. 1996, 54, 11169-11186.

(24) Kresse, G.; Hafner, J. Phys. Rev. B: Condens. Matter Mater. Phys. 1993, 47, 558-561.

(25) Kresse, G.; Hafner, J. Phys. Rev. B: Condens. Matter Mater. Phys. 1994, 49, 14251-14269.

(26) Kresse, G.; Hafner, J. J. Mater. Sci. 1996, 6, 15-50.

(27) Studt, F.; Abild-Pedersen, F.; Bligaard, T.; Sørensen, R. Z.; Christensen, C. H.; Nørskov, J. K. Angew. Chem., Int. Ed. 2008, 47, 9299-9302.

(28) Blöchl, P. E. Projector augmented-wave method. Phys. Rev. B: Condens. Matter Mater. Phys. 1994, 50, 17953-17979.

(29) Kresse, G.; Joubert, D. Phys. Rev. B: Condens. Matter Mater. Phys. 1999, 59, 1758-1775.

(30) Tan, T. L.; Wang, L.-L.; Johnson, D. D.; Bai, K. Nano Lett. 2012, 12,4875 .

(31) Sanchez, J. M.; Ducastelle, F.; Gratias, D. Phys. A 1984, 128, 334.

(32) von Pezold, J.; Dick, A.; Friák, M.; Neugebauer, J. Phys. Rev. B: Condens. Matter Mater. Phys. 2010, 81, 094203.

(33) Jedidi, A.; Markovits, A.; Minot, C.; Abderrabba, M. Chem. Phys. Lett. 2012, 541, 101.

(34) Jedidi, A.; Markovits, A.; Minot, C.; Abderrabba, M.; Van Hove, M. A. Phys. Chem. Chem. Phys. 2014, 16, 20703.

(35) Sinfelt, J. H.; Hurwitz, H.; Shulman, R. A. J. Phys. Chem. 1960, $64,1559-1562$.

(36) Jothimurugesan, K.; Bhatia, S.; Srivastava, R. D. Ind. Eng. Chem. Fundam. 1985, 24, 433-438.

(37) Pacheco, M. A.; Petersen, E. E. J. Catal. 1985, 96, 507-516.

(38) Sinfelt, J. H. J. Mol. Catal. A: Chem. 2000, 163, 123-128.

(39) Friend, C. M.; Muetterties, E. L. J. Am. Chem. Soc. 1981, 103, $773-779$.

(40) Alhumaidan, F.; Cresswell, D.; Garforth, A. Ind. Eng. Chem. Res. 2011, 50, 2509-2522.

(41) Poondi, D.; Vannice, M. A. J. Catal. 1996, 161, 742-751.

(42) Saeys, M.; Reyniers, M.; Thybaut, J. W.; Neurock, M.; Marin, G. B. J. Catal. 2005, 236, 129-138.

(43) Boudart, M.; Djéga-Mariadassou, G. Kinetics of Heterogeneous Catalytic Reactions; Princeton University Press: Ithaca, NY, 1984.

(44) Pal, A. K.; Bhowmick, M.; Srivastava, R. D. Ind. Eng. Chem. Process Des. Dev. 1986, 25, 236-241.

(45) Spanjers, C. S.; Sim, R. S.; Sturgis, N. P.; Kabius, B.; Rioux, R. M. ACS Catal. 2015, 5, 3304-3315. 